\title{
Highly Stable Precious Metal-Free Cathode Catalyst for Fuel Cell Application
}

\author{
Alexey Serov ${ }^{1,2}$, Michael J. Workman ${ }^{1}$, Kateryna Artyushkova ${ }^{1 *}$, Plamen Atanassov ${ }^{1}$, \\ Geoffrey $\mathrm{McCool}^{2}$, Sam McKinney ${ }^{2}$, Henry Romero $^{2}$, Barr Halevi ${ }^{2 *}$, Thomas \\ Stephenson $^{2}$ \\ ${ }^{1}$ University of New Mexico, Chemical \& Biological Engineering Department, Center for \\ Micro-Engineered Materials (CMEM), Albuquerque, NM 87131 (USA) \\ ${ }^{2}$ Pajarito Powder, Albuquerque, NM 87102 (USA) \\ * kartyush@unm.edu \\ *bhalevi@pajaritopowder.com
}

\section{Abstract}

A platinum group metal-free (PGM-free) oxygen reduction reaction (ORR) catalyst engineered for stability has been synthesized using the sacrificial support method (SSM). This catalyst was comprehensively characterized by physiochemical analyses and tested for performance and durability in fuel cell membrane electrode assemblies (MEAs). This catalyst, belonging to the family of $\mathrm{Fe}-\mathrm{N}-\mathrm{C}$ materials, is easily scalable and can be manufactured in batches up to $200 \mathrm{~g}$. The fuel cell durability tests were performed in a single cell configuration at realistic operating conditions of $0.65 \mathrm{~V}, 1.25$ atm $_{\text {gauge }}$ air, and 90\% RH for 100 hours. In-depth characterization of surface chemistry and morphology of the catalyst layer before and after durability tests were performed. The failure modes of the PGM-free electrodes were derived from structure-to-property correlations. It is 
suggested that under constant voltage operation, the performance loss results from degradation of the electrode pore structure, while under carbon corrosion accelerated test protocols the failure mode is catalyst corrosion.

\section{Introduction}

The continued development of fuel cell technology has facilitated the beginning of true commercialization of the technology. To foster growth of fuel cells as a commercial product, increased economic viability is necessary. As production volume increases, production cost of many of the components will decrease. However, the cost of platinumbased catalysts accounts for approximately $40 \%$ of the current fuel cell cost and will not decrease with increased production volume. The two primary approaches to reducing fuel cell cost are drastic reduction of Pt group metals (PGM) in the cathode, or completely replacing them with PGM-free catalysts. Several classes of PGM-free catalysts currently exist. The most promising of these for the oxygen reduction reaction (ORR) in the lowtemperature proton exchange membrane (PEMFC) type of fuel cell is based on metalnitrogen-carbon (M-N-C, where $\mathrm{M}=\mathrm{Fe}, \mathrm{Ni}, \mathrm{Co}$, and $\mathrm{Mn}$ ) composites with metal-nitrogen active sites embedded in stacked carbon graphitic sheets [1-3]. The performance of some M-N-Cs has been recently reported to be on the order of $10-20 \%$ that of platinum catalysts, showing great potential. However, the durability data reported in the open literature reveals insufficient stability of this class of materials in real fuel cell tests.[1, 46] Herein we report the first catalyst specifically developed for high stability that exhibits the necessary activity for a commercially viable PGM-free ORR catalyst in lowtemperature PEMFCs. 
The technology underlying the catalyst was invented by the University of New Mexico[4, 7-10], scaled-up and modified by Pajarito Powder, LLC with characterization input from collaborators including Scott Calabrese Barton[7], Sanjeev Mukerjee[11, 12], and Piotr Zelenay [13]. Catalysts based on this technology have been previously extensively characterized.[10] The sacrificial support method (SSM) used to synthesize this electrocatalyst from iron and nitrogen-carbon precursors results in an intrinsically PGM-free material. SSM synthesis produces material with multiple surface defects within a carbonaceous network and an internal network of connected pores with tunable size distribution. The key chemical features of these electrocatalysts that result in their high activity and excellent stability include: 1) the absence of free large iron/iron oxide particles, 2) the presence of graphite-protected iron and iron carbide species, and 3) the dominant iron species being atomically dispersed iron coordinated to nitrogen homogeneously distributed throughout the nitrogen-enriched carbon network. The formulations, processing and treatment conditions of catalyst layer were optimized for PEM membrane electrode assembly (MEA) performance for $\mathrm{H}_{2} /$ Air configuration and confirmed by desired physical-chemical properties. This paper presents the performance and characteristics of a PEMFC catalyst, which is the first PGM-free catalyst to demonstrate excellent stability for over 100 hours at representative realistic operating conditions of $0.65 \mathrm{~V}, 1.25 \mathrm{~atm}_{\text {gauge }}$ air, and $90 \%$ relative humidity (RH). In addition, electrode chemical and three-dimensional morphological post-mortem analysis was used to identify the failure modes for the PGM-free electrode and MEA itself.

\section{Experimental}


The catalyst was synthesized using a modified version of the SSM as described in the literature. $[7,10,14,15]$ The specific reagent formulation and processing procedure is proprietary technology developed by UNM and Pajarito Powder, LLC. MEAs (geometrical area: 5 and $50 \mathrm{~cm}^{2}$ ) were made from gas diffusion electrodes (GDEs) pressed with 211 Nafion $^{\circledR}$ membrane using PTFE-impregnated glass-fiber sub-gaskets at $131{ }^{\circ} \mathrm{C}$ for 10 minutes $\left(90 \mathrm{psi}\right.$ for $5 \mathrm{~cm}^{2}$ and $70 \mathrm{psi}$ for $50 \mathrm{~cm}^{2}$ sized electrodes, respectively), then allowed to cool down under 1 psi pressure. Sub-gasket thickness for the anode was $150 \mu \mathrm{m}$ and $250 \mu \mathrm{m}$ for the cathode. The GDE was sprayed using a SonoTek Exacta-Coat automated spray system delivering $4 \mathrm{ml} \mathrm{min}^{-1}$ ink through a $25 \mathrm{kHz}$ ultrasonic nozzle onto an SGL 25BC gas diffusion layer preheated to $65^{\circ} \mathrm{C}$. The ink was deposited at a rate of $40 \mu \mathrm{g} \mathrm{cm}^{-2}$ per deposition pass, for a total of $3 \mathrm{mg}_{\text {catalyst }} \mathrm{cm}^{-2}$ and 75 $\mu \mathrm{m}$ thick electrode. The inks were composed of 2:1 isopropyl alcohol:deionized water (v:v), catalyst, and D2021 Nafion ${ }^{\circledR}$ dispersion mixed to a ratio of $3.5 \mathrm{wt} \%$ solids. A $50 \mathrm{~mL}$ vessel containing the ink ingredients was placed in a water-cooled bath and mixed for 30 min using an IKA T-18 high shear mixer with the S18-19G dispersing element set at 18,000 RPM.

The MEAs were loaded into the cell testing assembly (Fuel Cell Technologies Inc.) using single $\left(5 \mathrm{~cm}^{2}\right)$ or triple $\left(50 \mathrm{~cm}^{2}\right)$ serpentine pattern graphite flow plates. The cell hardware was assembled using 40 inch-lbs torque for $5 \mathrm{~cm}^{2}$ and 50 inch-lbs for $50 \mathrm{~cm}^{2}$ cells. The cell was allowed to come up to $80{ }^{\circ} \mathrm{C}$ under a feed of $200 \mathrm{sccm}$ of $100 \% \mathrm{RH} 1.5 \mathrm{H}_{2} / 2.5 \mathrm{Air}$ and pressurized to a total of $1.70 \mathrm{~atm}_{\text {gauge. }}$ For the hold test, the load was applied potentiostatically to $0.65 \mathrm{~V}$ for $100 \mathrm{hrs}$ at steady state, then reduced to 0.6 and $0.4 \mathrm{~V}$ to allow comparison to previous steady-hold tests in the literature. 
Polarization curves were measured sequentially at 1.25, 2.5, 1.25, 0.5, and 4.5atm gauge air with potentiostatic tests with 60 seconds potential holds and the current at the end of the hold reported. Also, a fresh electrode was then subjected to a carbon corrosion accelerated test. The sample cell performance was measured in $\mathrm{H}_{2} /$ Air after 3 hours of polarization tests as described above; then the cathode feed was switched to $\mathrm{N}_{2}$. After 30 mins of flushing, an external power supply (Kiethley 2400) applied 5000 cycles of triangular wave $1.0-1.5 \mathrm{~V}, 500 \mathrm{mV} \mathrm{s}^{-1}$ linear sweeps. Air flow was resumed, and multiple polarization curves were measured. After 6 cycles performance stabilized and is reported.

Brunauer-Emmett Teller (BET) surface area (SA) measurements used a Micrometrics Gemini V system. The samples were degassed at $120^{\circ} \mathrm{C}$ for $10+\mathrm{hrs}$, and a 9 point analysis was used. Single and multipoint BET measurements for all samples were within $10 \%$ of each other, which is indistinguishable given the accepted accuracy of BET.

The pore size distribution (PSD) of the sprayed catalyst layer material was measured via mercury intrusion porosimetry (Micromeritics AutoPore IV 9500). A 3 mL penetrometer with a stem volume of $1.1 \mathrm{~mL}$ was loaded with $0.1 \mathrm{~g}$ of material. Mercury intrusion was measured over the pressure range of 0.1 to 30000 psi. The pressure is related to a pore radius with the Washburn equation: $r_{p}=2 \gamma \cos \theta / p_{\text {measured }}$ where the measured pressure $\left(p_{\text {measured }}\right)$, contact angle $(\theta)$, and surface tension of mercury $(\gamma)$, establish the pore radius $\left(r_{p}\right)$. In this way the change in mercury volume from one pressure to another can be associated with intrusion into a certain pore size and a pore size distribution can be calculated. 
Dynamic Light Scattering (DLS) measurement used a Microtrac Nanotrac 250 device. Pseudo-inks were prepared for DLS by mixing for 60 minutes in an IKA T-18 high shear mixer with S18-19G dispersing element at 18,000 RPM. The pseudo-ink consisted of $3.5 \mathrm{wt} \%$ solid catalyst in $50 \mathrm{~mL}$ of the same solvent composition as is used in the inks: 2:1 isopropyl alcohol:deionized water (v:v). The resulting pseudo-inks were diluted according to the instrument intensity requirements and measured at 3 aliquots.

Ashing tests were completed with 0.4-0.6 g of catalyst placed in a pre-weighed boat made of 309 stainless steel foil (boat weight $\sim 1.0 \mathrm{~g}$ ). The boat and catalyst were placed in a tube furnace (Lindberg TF55035A) with a 1" OD quartz tube liner with exhaust air pull. The furnace and sample were heated at $10{ }^{\circ} \mathrm{C} \mathrm{min}-1$ until $800{ }^{\circ} \mathrm{C}$, held for 10 mins, and allowed to cool. The boat and remaining sample were weighed. The remaining materials were analyzed by SEM/EDS and XRD. Control tests show that the boats gain less than $10 \mathrm{mg}$ after exposure to air, and none upon re-heating. Ashing tests were conducted in triplicate and averaged.

Inductively coupled plasma-atomic emission spectrometry (ICP-AES) was done by Green Analytical Laboratories (Durango, Colorado) using EPA6010B analysis method and EPA3050 digest method.

Scanning Electron Microscopy (SEM) was performed on a Hitachi S-5200 with $1.8 \mathrm{~nm}$ resolution at $1 \mathrm{kV}$ and Oxford Scientific EDS. The samples were prepared by dropping a small amount of catalyst and ethanol slurry onto an aluminum sample holder block and allowed to dry. The analysis was performed at $1 \mathrm{kV}$ and $5 \mu \mathrm{A}$. High Resolution Transmission Electron Microscopy (HRTEM) analysis was performed using a JEOL 2010F microscope with an accelerating voltage of $200 \mathrm{keV}$ and a current of $190 \mu \mathrm{A}$. 
X-ray photoelectron spectroscopy (XPS) analysis. The analysis was performed on pure catalyst powders, as well as on electrodes. Beginning of life (BOL) and end of life (EOL) MEAs were analyzed using a Kratos Axis DLD Ultra spectrometer using a monochromatic Al $\mathrm{K} \alpha \mathrm{X}$-ray source, with emission voltage of $15 \mathrm{kV}$ and emission current of $10 \mathrm{~mA}$. High-resolution spectra for carbon, fluorine, oxygen, and nitrogen were acquired to study the chemistry of the catalyst and Nafion ${ }^{\circledR}$ ionomer in catalyst layers. All powders and catalyst layers were conductive and mounted using conductive double-sided tape. No use of charge neutralization was necessary, resulting in unambiguous peak positions of spectra for accurate peak identifications. High-resolution spectra were curve-fit using individual symmetrical peaks to develop speciation information. $[11,16]$

Focused Ion Beam (FIB) sectioning. The MEAs were analyzed with an FEI Quanta 3D Dual beam scanning electron microscope equipped with a field emission gun (SEM-FEG). A series of 95-100 images was made at intervals of $30 \mathrm{~nm}$ where the thickness of the layer was about $2 \mu \mathrm{m}$. The FIB consisted of $\mathrm{Ga}^{+}$ions that were accelerated with a voltage of $30 \mathrm{kV}$. This was followed by SEM imaging of the surface for each slice with an accelerating voltage of $5 \mathrm{kV}$. The first step of image processing includes automatic registration in ImageJ [17] plug-in (StackReg) which is based on TurboReg [18] using the "Translation" option. During the second step, background filtering is applied in which uneven background and noise are removed using FFT bandpass filtering. Roughness was calculated from the original gray scale intensity. For the other 3D metrics, images were thresholded such that solid material has a value of intensity 1 and pores have a value of intensity 0 . Porosity is a ratio of void volume 
(pores) to total volume. Euler number of a 3D stack is a total number of objects (solid phase) in the stack minus the total number of holes (pores) in those objects. The Euler number is a measure of connectivity of solid phase. Solid phase size measured as average run (AR) length is the number of consecutive pixels representing solid phase cluster in a given direction. Average diffusion distance (ADD) is the average distance from a solid phase pixel to the nearest pore pixel in the image representing the average pore size.

\section{Results and Discussion}

Particle size distribution by DLS with SEM confirmation is shown in Figure 1, with detected sizes ranging from $0.3-1.0 \mu \mathrm{m}$, and outliers up to $2 \mu \mathrm{m}$ seen. The DLS measured particle sizes are in good agreement with the SEM observations (Figure $1 \mathrm{~b}$ ), where $10 \mathrm{~K}$ magnification shows agglomerates and particles ranging from $100 \mathrm{~nm}$ up to $2 \mu \mathrm{m}$, except that the smaller particles seen by SEM are not detected by DLS. This suggests that the suspensions measured in DLS are not allowing for full de-agglomeration of the catalyst particles.

Pore size distribution (PSD) is shown in Table 1, where mercury porosimetry [7], HRTEM and higher magnification 60K SEM image (Figure $1 \mathrm{c}$ ) show three different characteristic pore sizes: a small narrow pore size around $5 \mathrm{~nm}$ radius and a broad pore mode at around $300 \mathrm{~nm}$ radius (for neat catalyst) with a shoulder representing another characteristic pore size at a slightly smaller $100 \mathrm{~nm}$ radius. The HRTEM image (Figure 1 d) shows the expected open frame well-ordered structure without visible metallic particles, although the non-statistical nature of HRTEM does not completely preclude the presence of nanoparticles 
a)
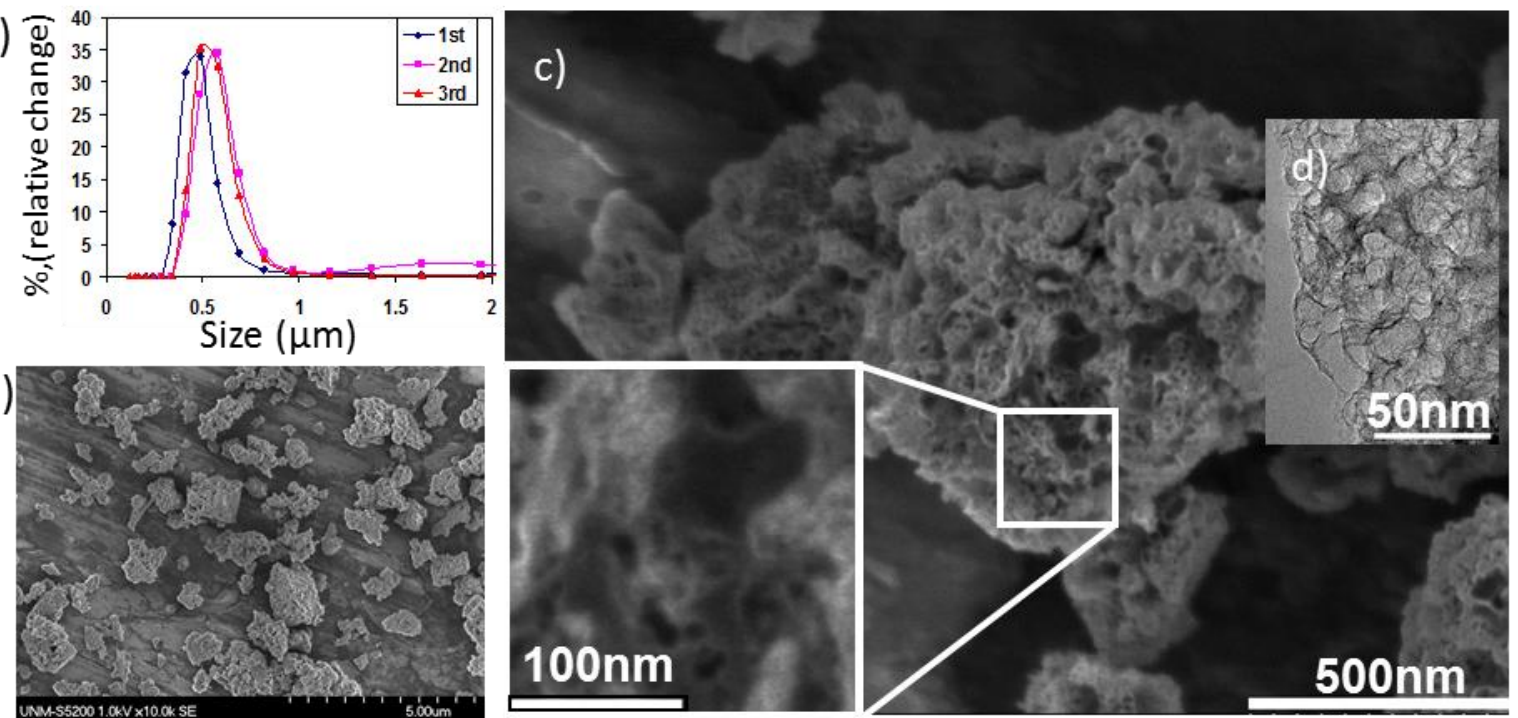

b)

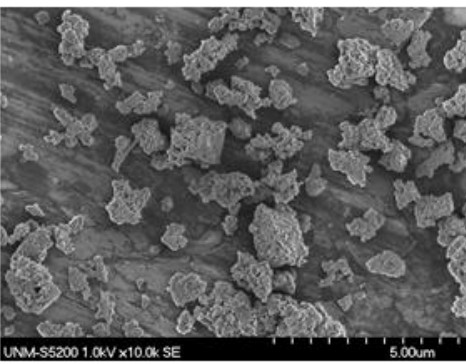

$100 \mathrm{~nm}$

$500 \mathrm{~nm}$

Figure 1. a) Particle size distribution by DLS. Three replicate runs shown. Size ranges between 0.3-1.0 $\mu \mathrm{m}$; b) and c) SEM images at two different magnifications show agglomerates between $100 \mathrm{~nm}$ and $2 \mu \mathrm{m}$ and d) high resolution TEM images showing open frame network.

The PSD measurement modes match well with the SEM observations except that the $20-40 \mathrm{~nm}$ pores evident by SEM are not measured. This can easily be explained by elongated pores, where the narrow aspect is in the $20-40 \mathrm{~nm}$ range, and the long aspect is in the $120-160 \mathrm{~nm}$. The $300 \mathrm{~nm}$ pores are in fact voids between the particles, and similarly, external contributions to the other pore modes are also likely.

Table 1 Pore size distribution analysis [7]

\begin{tabular}{|l|l|l|}
\hline Parameter & Pore Mode & Catalyst \\
\hline \multirow{2}{*}{$\begin{array}{l}\text { Mean Radius } \\
\text { nm }\end{array}$} & 1 & $4.6 \pm 0.1$ \\
\cline { 2 - 3 } & 2 & $160 \pm 10$ \\
\cline { 2 - 3 } Spread & 3 & $310 \pm 10$ \\
\cline { 2 - 3 } & 2 & $0.22 \pm 0.01$ \\
\cline { 2 - 3 } & 3 & $1.12 \pm 0.04$ \\
\hline \multirow{2}{*}{$\begin{array}{l}\text { Volume } \\
\text { fraction }\end{array}$} & 1 & $0.32 \pm 0.03$ \\
\cline { 2 - 3 } & 2 & $0.19 \pm 0.03$ \\
\cline { 2 - 3 } & 3 & $0.15 \pm 0.02$ \\
\hline
\end{tabular}


ICP analysis reports $0.3 \mathrm{wt} \% \mathrm{Fe}(1.3 \mathrm{at} \% \mathrm{Fe})$ while metal content analysis from ashing indicates $0.6 \mathrm{wt} \% \mathrm{Fe}(2.7 \mathrm{at} \% \mathrm{Fe})$. Since the digest used for ICP is likely not dissolving all the iron buried in the carbon matrix, it is expected that the ICP measurement is somewhat understating the iron content while residual iron carbide and silica made during the ashing tests is leading to overstating the iron content. Thus, the realistic iron content in the sample is between $0.4-0.5 \mathrm{wt} \% \mathrm{Fe}$, which corresponds to $\sim 2$ at $\%$ Fe. In this catalyst extra leaching was used to reduce iron content, and since the fuel cell performance did not change after this aggressive leaching, it is likely that observed catalytic activity arises from $\mathrm{FeN}_{\mathrm{x}} \mathrm{C}_{\mathrm{y}}$ type active sites. These sites are composed of atomically dispersed iron coordinated with nitrogen sites and embedded in carbon sheets. $\mathrm{FeN}_{\mathrm{x}} \mathrm{C}_{\mathrm{y}}$ sites have been shown to be active site towards $4 \mathrm{e}^{-}$reduction of oxygen, while $\mathrm{Fe}$ nanoparticles are selective to the $2 \times 2 \mathrm{e}^{-}$reduction of oxygen.[19] The combination of XRD and high resolution TEM shows that minor part of iron may be present as metallic $\mathrm{Fe}$ encapsulated in graphitic layers. It has been suggested before that this encapsulated iron may serve as the active site for ORR, or it may indirectly facilitate ORR by modifying electronic properties of carbon matrix. [19,20]

$X$-Ray Diffraction spectra with inset expansion of 20-50 $2 \theta$ in Figure 2 shows 5 main features: a broad peak $2 \theta 24.7$, a narrow peak at 26.4, a series of overlapping or one broad peak centered at 43.2, and a peak at 44.6. Another set of even broader overlapping peaks is evident at 81 . These peaks are consistent with graphite $(2 \mathrm{H})$, but it is possible that traces of graphite $3 R$ exist. Iron, iron oxides, and iron carbides are not evident. 


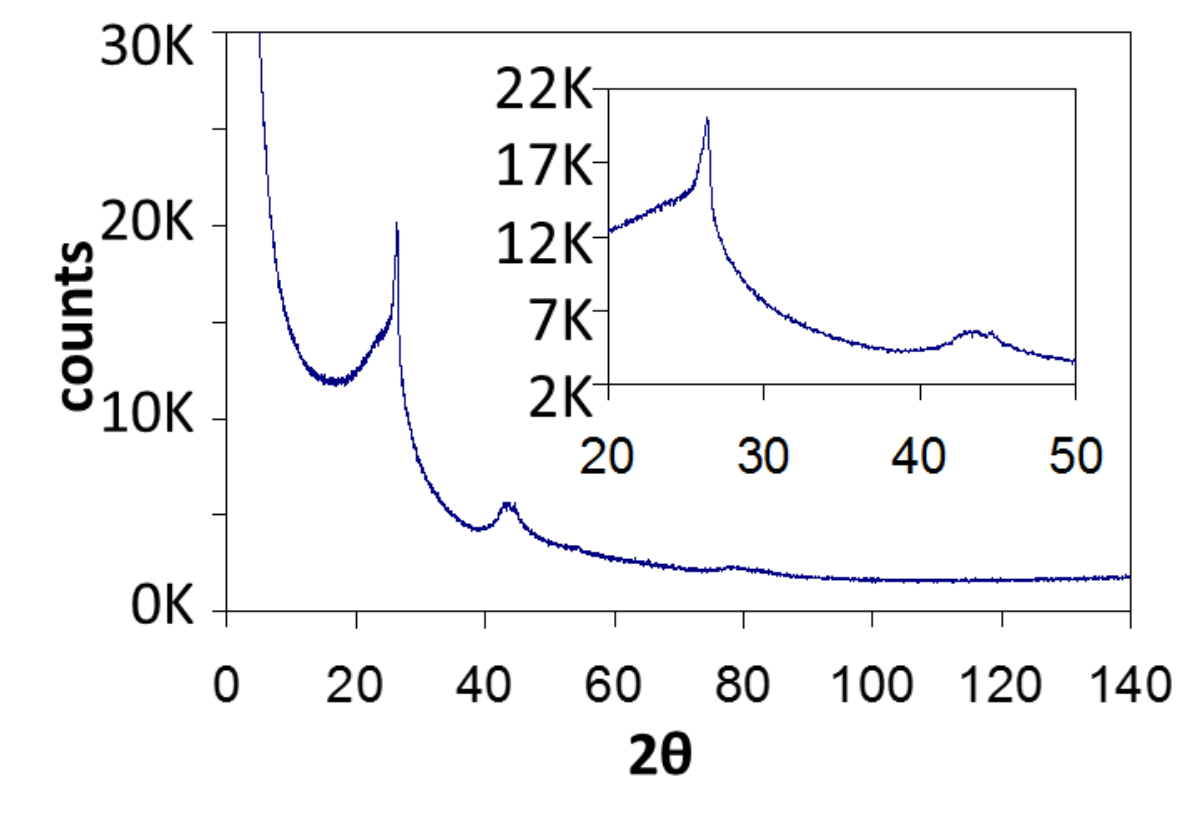

Figure 2. X-Ray Diffractogram showing graphitic carbon only. Inset shows zoom in from 20 to $502 \theta$. Signature is typical for graphite

\section{Single Cell Test}

MEA hold and carbon corrosion accelerated stress test (AST) polarization curves at $1.25 \mathrm{~atm}_{\text {gauge }}$ and $2.5 \mathrm{~atm}_{\text {gauge }}$ air, 100 and $90 \% \mathrm{RH}$ for beginning and end of life testing are shown in Figure 3. Approximately $30 \%$ of the performance at $0.6 \mathrm{~V}$ was lost between BOL and EOL as seen in the polarization curves for $90 \%$ RH (blue lines in Figure 3).

However, the lifetime test shows that the majority of the performance loss occurred during the first $10 \mathrm{hrs}$ of operation with minimal continuing loss up to $50 \mathrm{hrs}$.

Performance after 50 hours was completely stable at $50 \mathrm{~mA} \mathrm{~cm}{ }^{-2}$. As there is no $0.65 \mathrm{~V}$ hold test performance data available in the open literature, performance was also measured at 0.6 and $0.4 \mathrm{~V}$ at EOL. The performance of $390 \mathrm{~mA} \mathrm{~cm}^{-2}$ at $0.4 \mathrm{~V}$ in $1.25 \mathrm{~atm}_{\text {gauge }}$ air compares very favorably to previous reports of non-PGM catalyst performance in PEM, and in fact exceeds those significantly.[1, 5, 6] 

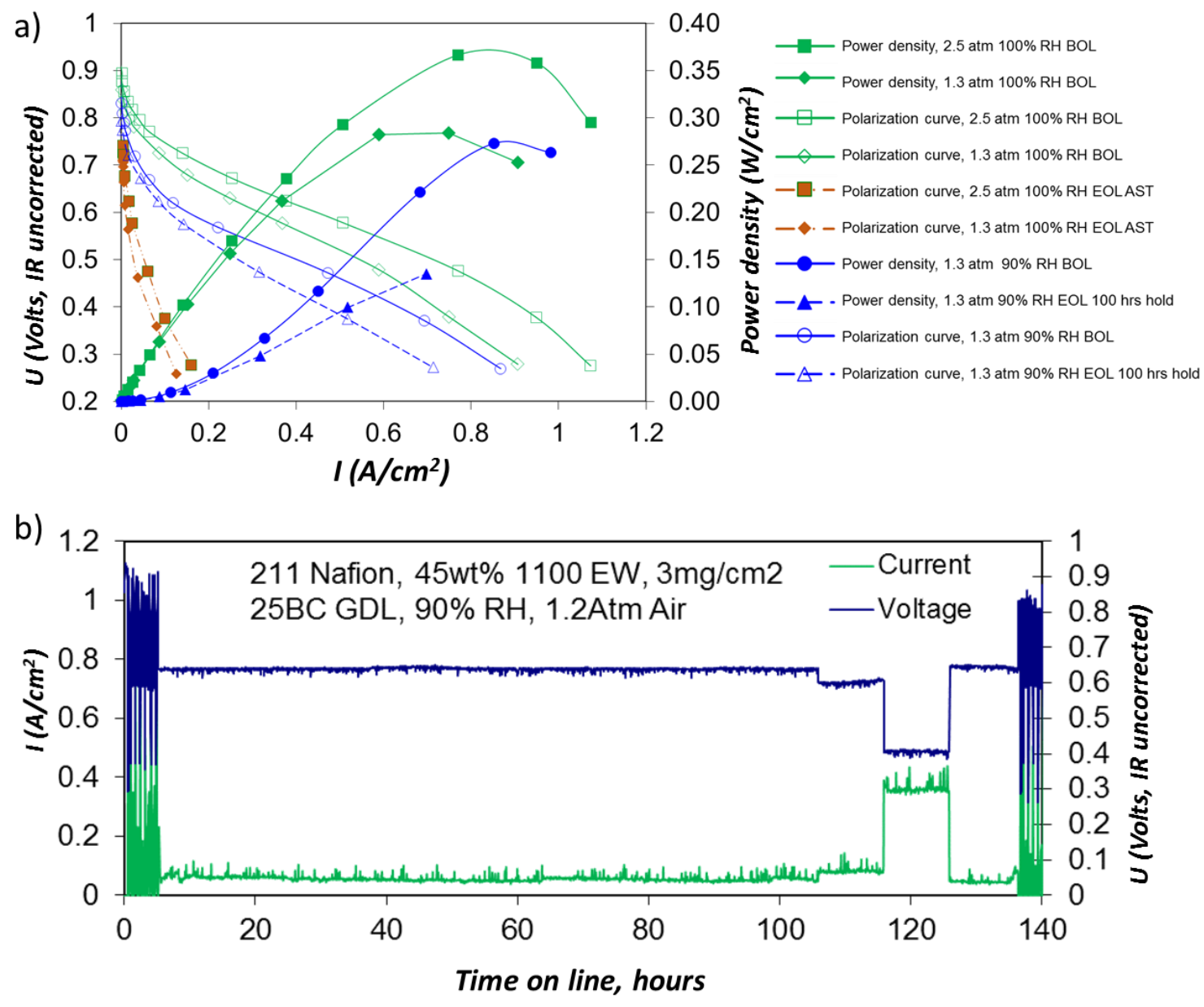

Figure 3. Potentiostatic hold test, top, and corresponding polarization curves, bottom. Solid lines indicate BOL, dashed EOL.

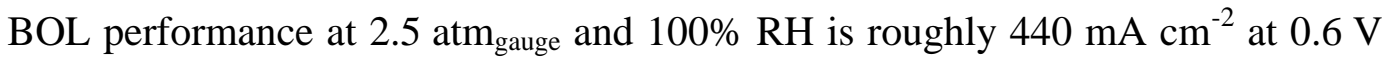
vs. $320 \mathrm{~mA} \mathrm{~cm}^{-2}$ a $1.25 \mathrm{~atm}_{\text {gauge }}$ (green lines in Figure 3). This indicates electrode losses beyond mere gas transport which may be due to flooding.[7] The corresponding peak power performance is $370 \mathrm{~mW}$ at $2.5 \mathrm{~atm}_{\text {gauge }}$ and $290 \mathrm{~mW}$ at $1.25 \mathrm{~atm}_{\text {gauge }}$. Reducing $\mathrm{RH}$ from $100 \% \mathrm{RH}$ to $90 \% \mathrm{RH}$ at BOL reduces current density at $0.6 \mathrm{~V}$ from $320 \mathrm{~mA} \mathrm{~cm}^{-2}$ to $190 \mathrm{~mA} \mathrm{~cm}{ }^{-2}$, while peak power density shifts down by $170 \mathrm{mV}$. This significant drop is not well understood and requires additional experiment. A likely cause is poor ionomer 
integration resulting in hindered proton transport. Studies to better understand the effects of humidity and water management for non-PGM catalyst electrodes are ongoing.

The carbon corrosion accelerated stress test $\left(5000\right.$ cycles of $1-1.5 \mathrm{~V}$ at $2 \mathrm{~V} \mathrm{~s}^{-1}$ in $\mathrm{H}_{2} / \mathrm{N}_{2}$ ) results show severe performance loss (brown lines in Figure 3), with OCV dropping by $200 \mathrm{mV}$ and current density at $0.4 \mathrm{~V}$ dropping to $60 \mathrm{~mA} \mathrm{~cm}{ }^{-2}$ at 1.25 atm gauge and $90 \mathrm{~mA} \mathrm{~cm}{ }^{-2}$ at $2.5 \mathrm{~atm}_{\text {gauge. }}$ This high rate of degradation is similar to $\mathrm{Pt} / \mathrm{C}$ catalysts and illustrates the need for improved carbon corrosion resistance for these catalysts when deployed in a system where $1.5 \mathrm{~V}$ incursions occur.

\section{Chemical composition analysis by XPS}

The chemical composition of catalyst powders, fresh catalyst layers, and post-tested ones was obtained by X-ray photoelectron spectroscopy (XPS). The near-surface sensitivity of XPS with sampling depth between $1.5 \mathrm{~nm}$ (for Fe) and $11 \mathrm{~nm}$ (for N) reveals the chemistry of interface that is accessible to the reactants. Tables 2 and 3 show the elemental composition and chemical speciation as obtained from high-resolution spectra. For the catalysts, only $\mathrm{C}, \mathrm{O}, \mathrm{N}$, and Fe were detected with 1.7 at\% nitrogen and 0.6 at\% iron present. In the catalysts layers, $\mathrm{F}$ and $\mathrm{S}$ were detected in addition to $\mathrm{C}, \mathrm{O}$ and N. Iron was not detected in the catalyst layers because of a) the low concentration and b) overlap of the fluorine inelastic background peak with the Fe 2p peak. The compositions of the catalyst layers after the two types of testing show only slight changes, with a small increase in $\mathrm{F}$ and $\mathrm{O}$ composition after the test. 
Table 2. XPS elemental composition analysis summary

\begin{tabular}{|l|cccccc|}
\hline & C 1s & F 1s & N 1s & O 1s & S 2p & Fe 2p \\
\hline BE, eV & & & & & & \\
\hline Catalyst & 94.6 & ND & 1.7 & 3.6 & ND & 0.6 \\
Fresh CL & 43.8 & 49.2 & 0.83 & 5.6 & 0.57 & ND \\
130 h CL & 40.8 & 52.1 & 0.79 & 5.8 & 0.47 & ND \\
AST CL & 41.1 & 51.0 & 0.73 & 6.8 & 0.41 & ND \\
\hline
\end{tabular}

Table 3. XPS chemical speciation analysis summary

\begin{tabular}{|c|c|c|c|c|c|c|c|c|}
\hline \multirow[b]{2}{*}{$\mathrm{BE}, \mathrm{eV}$} & $\begin{array}{l}\text { Cgr- } \\
\text { C-C }\end{array}$ & $\mathrm{C}_{\mathrm{x}} \mathrm{O}_{\mathrm{y}}$ & $\begin{array}{l}\mathrm{CF}_{\mathrm{x}} \\
\text { onomer }\end{array}$ & $\mathbf{C}_{\mathrm{x}} \mathbf{F}_{\mathrm{y}} \mathbf{O}_{\mathrm{z}}$ & $\begin{array}{c}\mathrm{N} \\
\text { pyrid }\end{array}$ & $\mathbf{N}_{\mathbf{x}}-\mathrm{Me}$ & $\begin{array}{l}\text { pyrrol - } \\
\text { graph }\end{array}$ & NO \\
\hline & $\begin{array}{l}284.4- \\
285.4\end{array}$ & $\begin{array}{r}286.5- \\
290.3\end{array}$ & $\begin{array}{c}291.7- \\
293\end{array}$ & $\begin{array}{c}294.4- \\
296\end{array}$ & 398.8 & 399.6 & $\begin{array}{c}400.5- \\
403.5\end{array}$ & 405.2 \\
\hline Catalyst & 75.6 & 24.4 & & & 14.8 & 8.6 & 67.4 & 6.1 \\
\hline Fresh CL & 28.0 & 16.2 & 51.8 & 4.1 & 2.9 & 8.8 & 79.4 & 5.2 \\
\hline $130 \mathrm{~h} \mathrm{CL}$ & 20.5 & 15.6 & 56.7 & 7.2 & 2.8 & 4.6 & 84.1 & 7.2 \\
\hline AST CL & 17.3 & 20.7 & 54.1 & 7.9 & 3.6 & 10 & 77.2 & 7.9 \\
\hline
\end{tabular}

Figure 4 shows high-resolution $\mathrm{C}$ 1s spectra from the pristine catalyst and fresh and tested catalyst layers, while Table 3 contains quantitative information on the relative amounts of different types of carbon. There are multiple peaks in high resolution $\mathrm{C} 1 \mathrm{~s}$ spectra due to different chemical species that have unique chemical shift. These chemical species can be grouped into four major groups of carbon: $\mathrm{C}-\mathrm{C} / \mathrm{C}=\mathrm{C}$ network, surface oxides such as $\mathrm{C}-\mathrm{OH}, \mathrm{C}-\mathrm{OC}, \mathrm{C}=\mathrm{O}$, etc., fluorinated part of ionomer $\mathrm{CF} / \mathrm{CF}_{2}$ and oxidized 
ionomer. The relative amounts of peaks at $284.4 \mathrm{eV}$ and $285.0 \mathrm{eV}$ are added together to represent the graphitic portion of the catalyst. A set of peaks between $286.5 \mathrm{eV}$ to $290.3 \mathrm{eV}$ are due to $\mathrm{C}-\mathrm{N}$ and $\mathrm{C}_{\mathrm{x}}-\mathrm{O}_{\mathrm{y}}$ groups within the catalyst. Relative amounts of these peaks are added together to represent all surface oxides present in the catalyst labeled as $\mathrm{C}_{\mathrm{x}} \mathrm{O}_{\mathrm{y}}$. Peaks at $291.7 \mathrm{eV}$ and $293.0 \mathrm{eV}$ are due to $\mathrm{C}-\mathrm{F}$ and $\mathrm{CF}_{2}$ groups in the ionomer, and they are grouped together into one group labeled $\mathrm{CF}_{\mathrm{x}}$ ionomer. Finally, the peaks at the highest binding energy between 294.4 and $296.0 \mathrm{eV}$ come from oxidized fluorinated groups in the ionomer and are added together into a group labeled $\mathrm{C}_{\mathrm{x}} \mathrm{F}_{\mathrm{y}} \mathrm{O}_{\mathrm{z}}$.
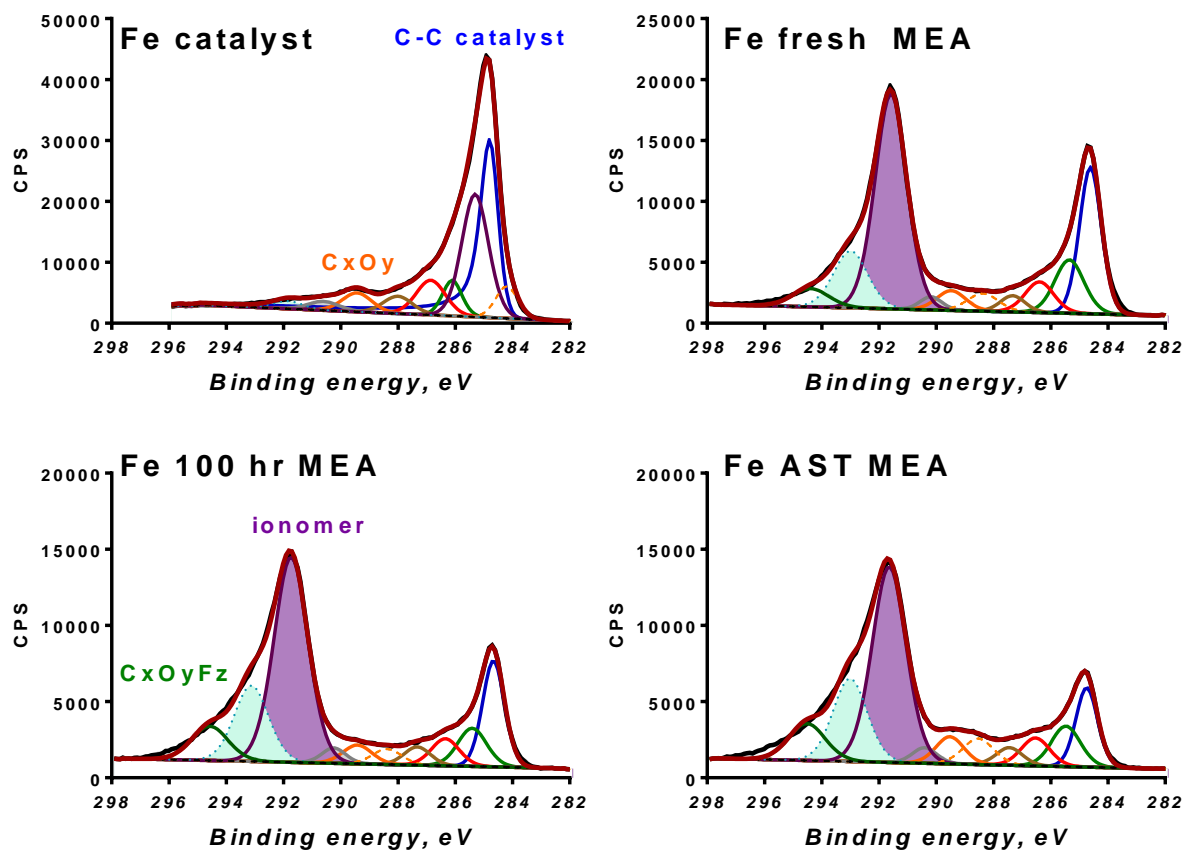

Figure 4. High resolution C 1s spectra for catalyst powder and catalyst layers - fresh, after 130 hours, and after AST protocol. Highlighted peaks are due to C-Fx groups in ionomer.

Very little change in the distribution of carbon species in both catalyst and ionomer part of the spectra is observed after testing. Minor oxidation of carbon in the catalyst layer is observed, especially for the AST-tested sample. After testing, ionomer constitutes 
the larger part of the overall carbon signal due to rearrangement of ionomer in the catalyst layer and some loss of catalyst at the surface as manifested by the decrease in the amount of nitrogen detected. Slight oxidation of ionomer is also observed. These insignificant changes in carbon structure demonstrate the stability of the composition of this catalyst ink in fuel cell operation.
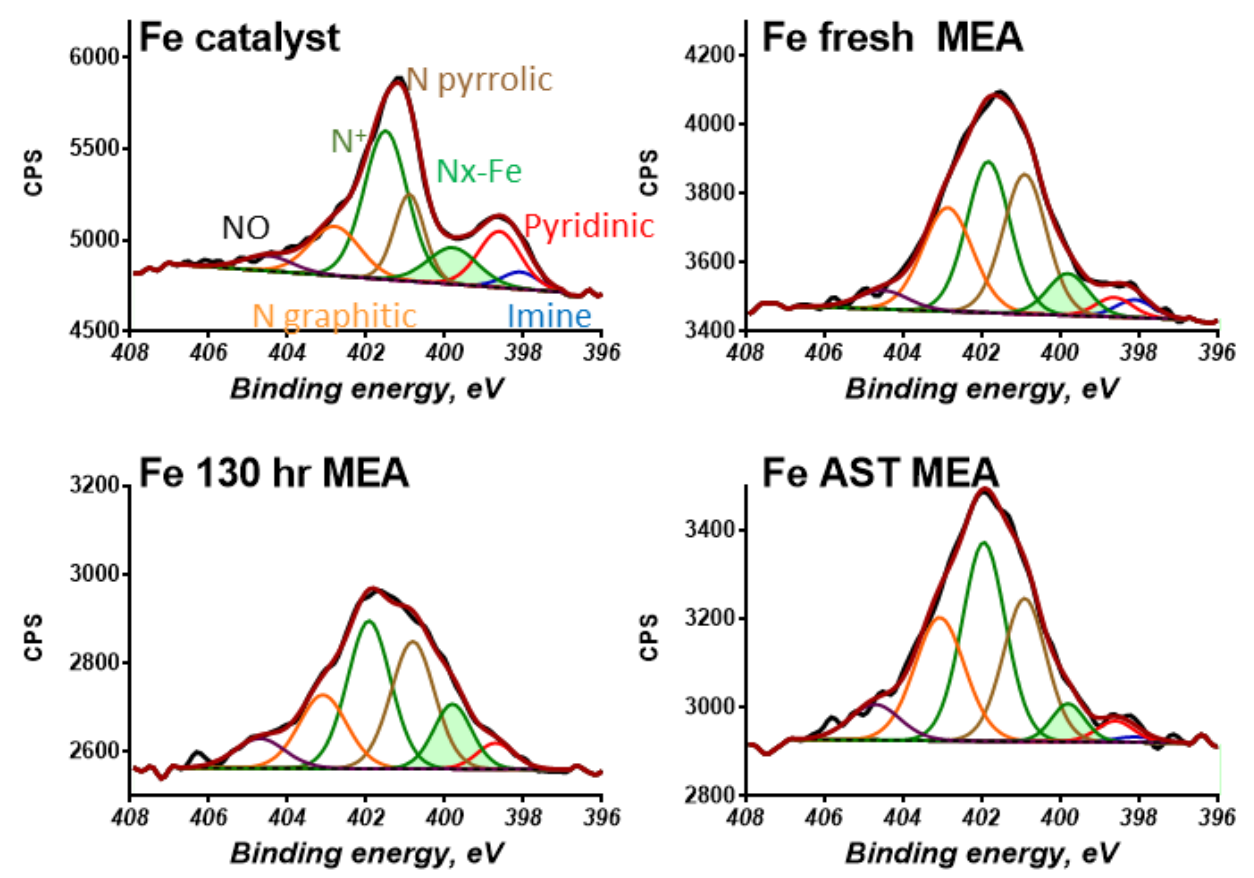

Figure 5. High resolution N 1s spectra for catalyst powder and catalyst layers - fresh, after 130 hours, and after AST protocol. 7 peaks are used to curve fit spectra. Highlighted peak is due to nitrogen coordinated to iron. Rearrangement of nitrogen species is observed in catalyst layers due to interaction with ionomer.

Figure 5 represents high-resolution $\mathrm{N}$ 1s spectra from the catalyst itself as well as three catalyst layers. Table 3 shows the quantitative distribution of nitrogen species. The catalyst powder shows the typical distribution of species, with lower binding energy peaks due to pyridinic nitrogen and nitrogen coordinated to iron. [21] Three peaks between 400.5 and $403.5 \mathrm{eV}$ are due to pyrrolic, graphitic and protonated nitrogen. The small peak due to NO is also present. Previous detailed structure-to-property analyses 
using XPS, XAS, and Mössbauer spectroscopy show that observed ORR activity is most likely linked to the Fe- $\mathrm{N}_{\mathrm{x}}-\mathrm{C}$ sites. $[10,21]$ In these previous works, in-situ XAS was used to confirm that oxygen adsorbs onto these $\mathrm{Fe}-\mathrm{N}_{4}-\mathrm{C}$ sites, and mechanistic studies showed that the $4 \mathrm{e}^{-}$reaction is dominant for these active sites. Other Fe- $\mathrm{N}_{\mathrm{x}}$ sites with XPS binding energy similar to pyridinic nitrogen have also been suggested to be active towards the oxygen reduction reaction. [21,22] Finally, pyrrolic and graphitic nitrogen have shown to be active only towards the partial reduction of oxygen to hydrogen peroxide.

When catalyst powder interacts with ionomer, there is a shift in BE of the spectra peaks towards higher binding energy due to the interaction between nitrogen at the surface of catalyst and the sulfonate groups in the ionomer. Also possible is the formation of protonated nitrogen moieties. The distribution of nitrogen species in the catalyst layer after the carbon corrosion AST testing is almost unchanged while a slight reduction of total nitrogen with a larger relative amount of graphitic nitrogen is observed after $130 \mathrm{hr}$ testing.

Morphological properties of catalyst layers in MEAs were investigated using the focused ion beam-scanning electron microscope (FIB/SEM). [23-27] A threedimensional reconstruction of catalyst layers provides critical information about the internal morphology of the layer at BOL and EOL. Figure 7 a) shows visualized 3D volumes of pores in fresh and post-mortem catalyst layers where pores are presented as color surrounded by transparent solid. Through visual inspection, it is obvious that there are fewer pores in the tested sample, but no information on specific pore distribution of morphological changes is evident. We extracted useful information from the 3D representation of catalyst layers by calculating key structural parameters such as overall 
roughness, porosity, connectivity, average solid phase size, and average pore size. Figure 6 b) displays the metrics calculated from 3D volume stacks - roughness, porosity, connectivity, and percent change in solid phase size and pore size after test with respect to BOL.

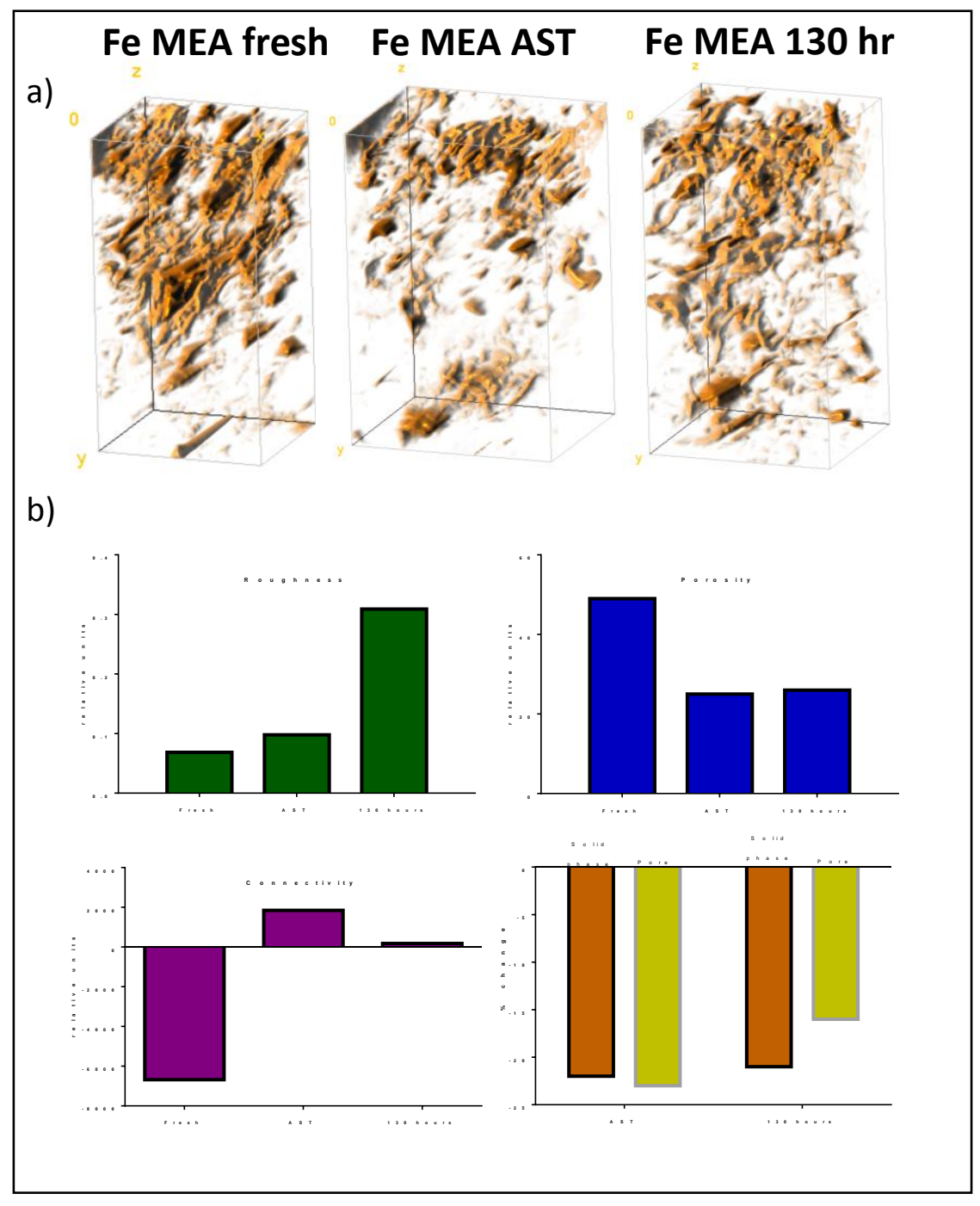

Figure 6. a) -Visualized FIB volumes representing 3D pores within solid material. Color represents pores surrounded by transparent solid. b) - 3D metrics extracted from 3D volumes for fresh and tested MEAs.

Roughness calculated from 3D volumes represent overall morphology. This volumetric parameter is calculated from intensity values within each 3D stack. 
Roughness increases after testing, especially after the $130 \mathrm{hr}$ test.

All other metrics were calculated from thresholded 3D stacks. As described in the Experimental section, thresholding is done to represent solid phase by the value of intensity 1 and pores by the value of intensity 0 . Porosity is a ratio of void volume (pores) to total volume. Roughness increases while overall porosity decreases during testing.

The Euler number of a 3D stack is a measure of connectivity of the solid phase. The more connected the network, the more negative the value is. Both MEAs show loss of connectivity at EOL.

Areal metrics such as average solid phase size and average pore size may be responsible for transport phenomena. Solid phase size measured as the average run (AR) length is the number of consecutive pixels representing the solid phase cluster. Average between-cluster distances calculated as average diffusion distance (ADD) is the average distance from a solid phase pixel to the nearest void (pore) pixel in the image. This is a measure of pore size between solid phase clusters. The solid phase size and pore size were measured at the BOL and EOL. It is observed that there is a decrease in both pore size and solid phase size. These calculated morphological changes quantified by digital image processing are manifestations of catalyst layer collapse.

In summary, chemical and post-mortem morphological analysis of catalyst layers reveals stability of the chemical composition of both catalyst and ionomer and small collapse in catalyst layers after $0.65 \mathrm{~V}$ voltage hold tests. The 1-1.5 V carbon corrosion accelerated stress tests, however, lead to significant catalyst corrosion. 


\section{Conclusions}

The cost of platinum-based catalysts creates demand for developing active and durable alternative, precious metal-free, catalysts. Here we report on the first precious metal-free catalyst specifically developed for commercialization, with viable cost, stability, and scalability. The M-N-C type precious metal-free oxygen reduction catalyst was developed from a technology pioneered by the University of New Mexico and scaled up to 200 grams per batch. The catalyst was characterized and tested in MEA, demonstrating excellent stability over 100 hours at representative realistic operating conditions of $0.65 \mathrm{~V}, 1.25$ atm $_{\text {gauge }}$ air, and 90\% RH. Electrode cross-sectioning analysis was used to identify the failure modes for the PGM-free electrode and MEAs. The analysis results show that under operating voltage hold, the failure mode is electrode/MEA structure collapse, while under carbon corrosion accelerated test protocols $\left(1-1.5 \mathrm{~V}, \mathrm{H}_{2} / \mathrm{N}_{2}, 5000\right.$ cycles $)$ the failure mode is catalyst corrosion. These indicate the need for both improved electrode construction and catalysts with improved corrosion resistance.

While there is still, of course, a need for improvements in catalyst performance, this is the first reported instance of a catalyst that begins to demonstrate the type of stability and activity necessary for a commercial PGM-free ORR catalyst for low-temperature PEMFC. Improved catalysts derived from the catalyst described in this work are available for purchase from Pajarito Powder.

\section{Acknowledgements}


We gratefully acknowledge support from USA DoE DE-EE0000459 and NSF GRFP Grant No. 1418062.

\section{References}

[1] R. Bashyam, P. Zelenay, Nature (London, U. K.), 443 (2006) 63-66.

[2] F. Jaouen, E. Proietti, M. Lefevre, R. Chenitz, J.-P. Dodelet, G. Wu, H.T. Chung,

C.M. Johnston, P. Zelenay, Energy Environ. Sci., 4 (2011) 114-130.

[3] D. Villers, X. Jacques-Bedard, J.-P. Dodelet, J. Electrochem. Soc., 151 (2004) A1507-A1515.

[4] B. Piela, T.S. Olson, P. Atanassov, P. Zelenay, Electrochim. Acta, 55 (2010) 76157621.

[5] G. Wu, C.M. Johnston, N.H. Mack, K. Artyushkova, M. Ferrandon, M. Nelson, J.S. Lezama-Pacheco, S.D. Conradson, K.L. More, D.J. Myers, P. Zelenay, J. Mater. Chem., 21 (2011) 11392-11405.

[6] G. Liu, X. Li, B. Popov, ECS Transactions, 25 (2009) 1251-1259.

[7] N.D. Leonard, K. Artyushkova, B. Halevi, A. Serov, P. Atanassov, S.C. Barton, Journal of The Electrochemical Society, 162 (2015) F1253-F1261.

[8] A. Serov, M.H. Robson, B. Halevi, K. Artyushkova, P. Atanassov, Electrochem. Commun., 22 (2012) 53-56.

[9] A. Serov, M.H. Robson, K. Artyushkova, P. Atanassov, Appl. Catal., B, 127 (2012) 300-306.

[10] A. Serov, K. Artyushkova, E. Niangar, C. Wang, N. Dale, F. Jaouen, M.-T. Sougrati, Q. Jia, S. Mukerjee, P. Atanassov, Nano Energy, (2015).

[11] U. Tylus, Q. Jia, K. Strickland, N. Ramaswamy, A. Serov, P. Atanassov, S. Mukerjee, J. Phys. Chem. C, 118 (2014) 8999-9008.

[12] A. Serov, K. Artyushkova, P. Atanassov, Adv. Energy Mater., 4 (2014) n/a.

[13] G. Wu, K.L. More, C.M. Johnston, P. Zelenay, Science, 332 (2011) 443-447.

[14] S. Stariha, K. Artyushkova, A. Serov, P. Atanassov, International Journal of Hydrogen Energy, 40 (2015) 14676-14682.

[15] A. Serov, K. Artyushkova, N.I. Andersen, S. Stariha, P. Atanassov, Electrochim. Acta, (2015) Ahead of Print.

[16] K. Artyushkova, S. Pylypenko, T.S. Olson, J.E. Fulghum, P. Atanassov, Langmuir, 24 (2008) 9082-9088.

[17] W.S. Rasband, in, U. S. National Institutes of Health, Bethesda, Maryland, USA, 1997-2014.

[18] P. Thévenaz, in, Swiss Federal Institute of Technology Lausanne.

[19] Q. Jia, N. Ramaswamy, U. Tylus, K. Strickland, J. Li, A. Serov, K. Artyushkova, P. Atanassov, J. Anibal, C. Gumeci, S.C. Barton, M.-T. Sougrati, F. Jaouen, B. Halevi, S. Mukerjee, Nano Energy, (2016).

[20] J.-P. Dodelet, R. Chenitz, L. Yang, M. Lefèvre, ChemCatChem, 6 (2014) 18661867.

[21] K. Artyushkova, A. Serov, S. Rojas-Carbonell, P. Atanassov, The Journal of Physical Chemistry C, (2015). 
[22] U.I. Kramm, I. Abs-Wurmbach, I. Herrmann-Geppert, J. Radnik, S. Fiechter, P. Bogdanoff, Journal of the Electrochemical Society, 158 (2011) B69-B78.

[23] J. Balach, F. Miguel, F. Soldera, D.F. Acevedo, F. MÜCklich, C.A. Barbero, Journal of Microscopy, 246 (2012) 274-278.

[24] N. Larouche, R. Chenitz, M. Lefevre, E. Proietti, J.-P. Dodelet, Electrochim. Acta, 115 (2014) 170-182.

[25] S. Stariha, K. Artyushkova, M.J. Workman, A. Serov, S. McKinney, B. Halevi, P. Atanassov, Journal of Power Sources, 326 (2016) 43-49.

[26] G. Zhang, S. Sun, D. Yang, J.-P. Dodelet, E. Sacher, Carbon, 46 (2008) 196-205.

[27] S. Zils, M. Timpel, T. Arlt, A. Wolz, I. Manke, C. Roth, Fuel Cells, 10 (2010) 966972. 


\section{Figure captions}

Figure 1. a) Particle size distribution by DLS. Three replicate runs shown. Size ranges between 0.3-1.0 $\mu \mathrm{m}$; b) and c) SEM images at two different magnifications show agglomerates between $100 \mathrm{~nm}$ and $2 \mu \mathrm{m}$ and d) high resolution TEM images showing open frame network.

Figure 2. X-Ray Diffractogram showing graphitic carbon only. Inset shows zoom in from 20 to $502 \theta$. Signature is typical for graphite

Figure 3. Potentiostatic hold test, top, and corresponding polarization curves, bottom. Solid lines indicate BOL, dashed EOL.

Figure 4. High resolution C 1s spectra for catalyst powder and catalyst layers - fresh, after 130 hours, and after AST protocol. Highlighted peaks are due to C-Fx groups in ionomer.

Figure 5. High resolution N 1s spectra for catalyst powder and catalyst layers - fresh, after 130 hours, and after AST protocol. 7 peaks are used to curve fit spectra. Highlighted peak is due to nitrogen coordinated to iron. Rearrangement of nitrogen species is observed in catalyst layers due to interaction with ionomer.

Figure 6. a) -Visualized FIB volumes representing 3D pores within solid material. Color represents pores surrounded by transparent solid. b) - 3D metrics extracted from 3D volumes for fresh and tested MEAs. 